\title{
Adsorption of NO in clinoptilolite-rich zeolitic mineral by concentration pulse chromatography method
}

\author{
Güler Narin*, Semra Ülkü \\ Department of Chemical Engineering, Izmir Institute of Technology, Urla, 35430, Izmir, Turkey
}

\section{A R T I C L E I N F O}

\section{Article history:}

Received 5 February 2016

Received in revised form

28 May 2016

Accepted 5 July 2016

Available online 7 July 2016

\section{Keywords:}

Natural zeolite

Nitric oxide

Adsorption

Diffusion

Chromatography

\begin{abstract}
A B S T R A C T
The equilibrium and kinetic parameters for NO adsorption in a clinoptilolite-rich natural zeolitic material from Turkey were determined using the concentration pulse chromatography method. Under the experimental conditions (carrier gas velocities and adsorption temperatures) the micropore diffusion resistance was found to be the mass transfer controlling step. Matching the first moment of the response peaks to the mathematical model the Henry's Law constants and heat of adsorption at zero loading were determined. The axial dispersion, external film, macropore and micropore diffusion coefficients, and activation energy for diffusion of NO in the micropores were calculated from the analysis of the second moments of the response peaks. For successive NO pulses without regeneration between the pulses, the retention times of the response peaks decreased and peak areas increased with the injection number indicating irreversible adsorption. The reversibly adsorbed NO could be desorbed by purging with an inert gas at the adsorption pressure and temperature. Temperature programmed desorption profile obtained by heating the NO saturated adsorbent to $400{ }^{\circ} \mathrm{C}$ under inert flow revealed presence of multiple irreversibly adsorbed species in NZ with different thermal stabilities. Desorption of these species was not achieved during the heating up to $400{ }^{\circ} \mathrm{C}$ which makes the natural zeolitic material suitable for NO storage rather than for cyclic adsorptive separation processes.
\end{abstract}

(c) 2016 Elsevier Inc. All rights reserved.

\section{Introduction}

Nitric oxide (NO) is an important gas from environmental and biological points of view. From the environmental perspective, nitrogen oxides ( $\mathrm{NOx}$ ) ( $\mathrm{NO}$ and $\mathrm{NO}_{2}$ ) are formed by combustion of fossil fuels and of concern because of their adverse effects on public health and the environment. NO typically constitutes $95 \%$ of the total NOx in the combustion products [1]. On the other hand, it is an extremely important molecule in biology as it plays role in regulation of diverse biological processes including vascular tone, neurotransmission, inflammatory cell responsiveness, defense against invading pathogens and wound healing. NO-storing solids have potential applications as antithrombotic materials [2].

Currently, three-way catalyst is employed for removal of NOx in emissions from mobile sources and selective catalytic reduction (SCR) of NOx with $\mathrm{NH}_{3}$ is applied for stationary sources. The most

\footnotetext{
* Corresponding author. Present address: Department of Chemical Engineering, Usak University, 64200, Usak, Turkey. Tel.: +90 2762212121.

E-mail addresses: guler.narin@usak.edu.tr (G. Narin), semraulku@iyte.edu.tr (S. Ülkü).
}

significant technical problems in SCR are poisoning of the catalyst and design of the ammonia injection system. Also, the use of ammonia generates problems due to leak and to the difficulties of transport and storage [3]. A variety of ion exchanged zeolites has been tested as catalyst for SCR in which ammonia or hydrocarbons are used as the reducing agent [4-18]. Several other methods have been investigated for elimination of NOx including catalytic decomposition [19-22], selective non-catalytic reduction (SNCR) [23] and NOx storage-reduction (NSR) [24,25].

Adsorption is a simpler method for the elimination of NOx. It allows NOx to be adsorbed and subsequently desorbed for the later treatment or direct application. Furthermore adsorption processes does not require additional reagents (e.g., $\mathrm{NH}_{3}$ ) and operate at lower temperatures $\left(<100{ }^{\circ} \mathrm{C}\right)$ [26]. The crucial point in performance of NOx adsorption processes is the efficiency of the adsorbent. The adsorbent should have a high adsorption capacity and high selectivity for NOx, and low desorption temperature for the ease of regeneration.

Adsorption is the primary step in catalytic reactions. NO adsorption in metal-free zeolites (ZSM-5, 13X, SAPO, Y, $\beta, \mathrm{NaY}, \mathrm{NaX}$, CaA, NaA, ferrierite, mordenite, USY, ZSM-22, MCM-22) [26,27-30], 
metal oxide-impregnated or metal (e.g. Cu, Co, Fe, H, Au, V) exchanged zeolites (e.g. Y, beta, ZSM-5, A type, MFI, MOR) have been examined for this purpose [31-47]. Zeolite-based catalysts including transition metal cations exhibited high efficiency in the removal of NOx. Recently commercial zeolites ( $\mathrm{NaX}, \mathrm{NaY})$ and their copper-modified analogues have been evaluated for $\mathrm{NO}_{2}$ and $\mathrm{NO}$ adsorption in the presence of moisture [48]. Chang et al. tested NOx adsorption capacity of unsupported $\mathrm{CaO}$ and beta zeolite modified with $\mathrm{CaO}, \mathrm{K}_{2} \mathrm{O}, \mathrm{MgO}, \mathrm{BaO}, \mathrm{ZnO}, \mathrm{MnO}, \mathrm{CeO}_{2}$ and $\mathrm{La}_{2} \mathrm{O}_{3}$ in the presence of $\mathrm{O}_{2}$ in the feed [49].

After the adsorbent is saturated with NOx, the adsorbed NOx must be desorbed for the adsorbent to be used again. The application of pressure swing adsorption (PSA) to regenerate the remove NOx-saturated adsorbent has been tested using several zeolites (MFI, mordenite, ferrierite, ZSM-5, offretite/erionite, Y, L, and X) exchanged with various metals ( $\mathrm{Na}, \mathrm{Ca}, \mathrm{Sr}, \mathrm{Ba}, \mathrm{Mg}, \mathrm{Cu}, \mathrm{Ag}, \mathrm{Mn}, \mathrm{Ni}$, $\mathrm{Zn}, \mathrm{Fe}, \mathrm{Cr}, \mathrm{Ce}, \mathrm{La}, \mathrm{Co}$ and $\mathrm{H}$ ) as the adsorbent [26,36-39]. The results of these studies revealed that the total, reversibly and irreversibly adsorbed NO amounts changed with the type and amount of the metal exchanged as well as the zeolite type [26].

Natural zeolites were proposed for gas purification applications rather than bulk separation due to their small pores and small pore volumes [50]. Clinoptilolite [51,52] and $\mathrm{NH}_{4}$-clinoptilolite [53] were applied in the removal of $\mathrm{NO}_{\mathrm{x}}$ from stack gases from fuel gas combustion processes. $\mathrm{N}_{2} \mathrm{O}$ and $\mathrm{NO}$ adsorption capacities of natural zeolites (erionite, mordenite, and clinoptilolite) from deposits in Mexico were measured in both static and dynamic regimes. The mordenite was found to be the most promising adsorbent for separating $\mathrm{N}_{2} \mathrm{O} / \mathrm{NO}$ mixtures [54]. The same research group calculated the isosteric heats of NO adsorption from the adsorption isotherms obtained at $0{ }^{\circ} \mathrm{C}$ and $20{ }^{\circ} \mathrm{C}$ as $15-46 \mathrm{~kJ} / \mathrm{mol}$ for mordenite, $15-32 \mathrm{~kJ} / \mathrm{mol}$ for erionite, and $16-37 \mathrm{~kJ} / \mathrm{mol}$ for clinoptilolite in the NO loading range of $0-0.7 \mathrm{mmol} \mathrm{NO} / \mathrm{g} \mathrm{[55].}$

Natural zeolites were also investigated as catalyst in $\mathrm{SCR}$ of $\mathrm{NO}_{\mathrm{x}}$. $\mathrm{Cu}$ (II)-exchanged mordenite and clinoptilolite were found to be very active catalysts using $\mathrm{NH}_{3}$ in excess oxygen and showed high water tolerance [56]. $\mathrm{Fe}^{3+}$-clinoptilolite was found to be more active than the commercial vanadia catalyst in SCR of NO with ammonia [57].

Design and optimization of adsorptive separation processes require the adsorption equilibrium and kinetic parameters. Gas chromatography offers an alternative to conventional gravimetric and volumetric methods for experimental adsorption equilibrium and kinetic studies due to its advantage sing [58]. The adsorption equilibrium and kinetic parameters can be derived by matching the experimental chromatograms to the mathematical model. Chromatography has been applied to determine NO adsorption kinetic and equilibrium parameters for various adsorbents in the literature. Clinoptilolite from Bigadiç region (Turkey) was found to be the most promising adsorbent for the separation of $\mathrm{NO}$ from $\mathrm{N}_{2}$ (air) among the molecular sieves tested, namely synthetic $\mathrm{H}$-mordenite, $4 \mathrm{~A}, 5 \mathrm{~A}$, and activated carbon [59]. In another study, higher Henry's law constants and heat of adsorption for NO on the clinoptilolite than on $4 \mathrm{~A}, 5 \mathrm{~A}$ and $\mathrm{H}$-mordenite were reported. Clinoptilolite gave the highest separation $\mathrm{NO} / \mathrm{N}_{2}$ factors at low concentrations [60]. Galán studied the adsorption of $\mathrm{NO}$ on $13 \mathrm{X}$ and $5 \mathrm{~A}$, alumina (boehmite) and nickel-kieselguhr and copper zinc oxide catalysts by using a chromatographic technique. The low NO adsorption capacity of $13 \mathrm{X}$ was explained by absence of interaction between NO molecules and $13 \mathrm{X}$ due to the low molecular size of NO in comparison with the effective pore diameter of $13 \mathrm{X}$ [61]. In another study, the diffusional resistances for NO were reported to decrease in the following order: natural mordenite $>$ Na-mordenite $>\mathrm{H}$ mordenite $>(13 \mathrm{X}, 5 \mathrm{~A})$ indicating the increased ease of flow in the 3-dimensional network. Isosteric heats of adsorption (range from
$12.6 \mathrm{~kJ} / \mathrm{mol}$ to $50.2 \mathrm{~kJ} / \mathrm{mol}$ ) and activation energies (range from $12.6 \mathrm{~kJ} / \mathrm{mol}$ to $79.6 \mathrm{~kJ} / \mathrm{mol}$ ) decreased in the same order. The differences of these parameters were discussed in terms of the interaction between the adsorbent surface and NO molecules as well as the pore size of the adsorbent relative to the size of the diffusing NO molecules [62].

Recently, synthetic zeolites (LTA and FAU zeolites) exchanged with different transition metal cations $\left(\mathrm{Na}^{+}, \mathrm{Ni}^{2+}, \mathrm{Cu}^{2+}, \mathrm{Zn}^{2+}, \mathrm{Co}^{2+}\right.$, and $\mathrm{Mn}^{2+}$ ) were applied for NO delivery purposes and NO-loaded zeolites exhibited biological activity. The mechanism of the biological effect was release of the loaded NO upon exposure of the NO-loaded zeolite to a moist atmosphere. NO-loaded zeolites were proposed as a cheap and simple alternative to other NO-releasing materials for use in medical applications [63-65].

The present study aims at determining NO adsorption equilibrium and kinetic parameters for a clinoptilolite-rich natural zeolitic material (NZ) from Gördes region (Turkey) using the concentration pulse chromatography method. The NO storage and release properties of this material have been previously examined by our group. In that study total, reversible and irreversible NO adsorption capacities of the material have been determined and it was shown that NZ can store and release NO thereby exhibits antibacterial/ bactericidal activity [66].

\section{Materials and methods}

\subsection{Material}

The natural zeolitic material from Gördes region (Turkey) was used as adsorbent in the present study. Preparation and characterization of the zeolitic material (NZ) have been reported in our previous study [66]. Briefly, NZ contains predominantly clinoptilolite (67 wt \%) as well as quartz, feldspars and biotite as mineral impurities. $\mathrm{NZ}$ is rich in potassium and has $\mathrm{SiO}_{2} / \mathrm{Al}_{2} \mathrm{O}_{3}$ ratio of 5.90 .

\subsection{Concentration pulse chromatography (CPC)}

Nitric oxide adsorption equilibrium and kinetic parameters for NZ were determined by the concentration pulse chromatography (CPC) method. This method is a dynamic method of conducting adsorption measurements, which measures the response of a chromatographic column to a pulse in adsorbate concentration.

CPC experiments were performed using the experimental setup shown in Fig. 1. The column was made from type 316 stainless steel tubing of $1 / 4$ inches in outer diameter. Commercially available

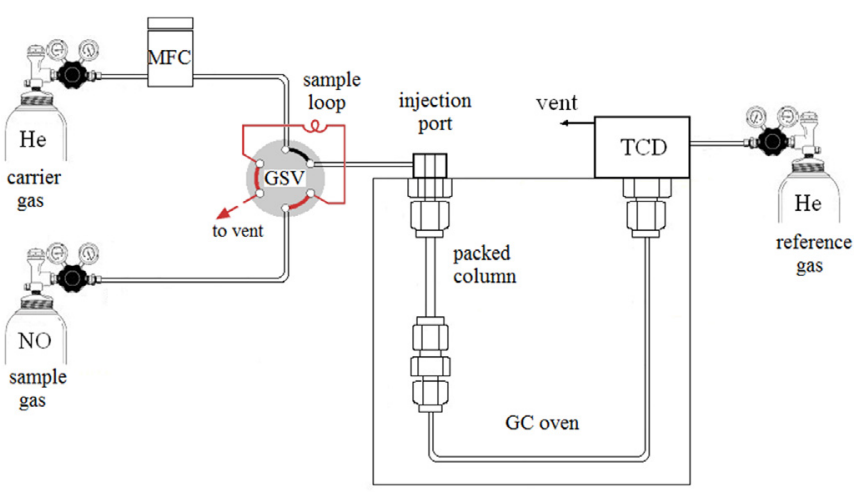

Fig. 1. Experimental set-up used in the concentration pulse chromatography experiments (MFC: mass flow controller, GSV: 6-port gas sampling valve, TCD: thermal conductivity detector). 
stainless steel pressed frits with pore size of $20 \mu \mathrm{m}$ were used at the ends of the column. The characteristics of the packed column were determined from the properties of the zeolites and from the dimensions of the system and are given in Table 1 . The mass of the zeolite packed into the column was determined from the difference of the mass of the column before and after the packing. The dehydrated mass of the zeolite in the bed was determined based on the thermogravimetric analyses (7.82\% mass loss was measured on heating up to $400{ }^{\circ} \mathrm{C}$ at a heating rate of $10^{\circ} \mathrm{C} / \mathrm{min}$, under $40 \mathrm{~mL} /$ min $\mathrm{N}_{2}$ flow).

The particle size distribution of NZ particles was measured using a particle size analyzer (Mastersizer 2000, Malvern Instruments). The particle density and total pore volume were determined using a specimen of rectangular prism of zeolitic material. The true solid density was measured by a helium pycnometer (Ultrapycnometer 1000, Quantachrome). The particle porosity was calculated by subtracting the micropore volume from the total pore volume. The micropore volume was determined from $\mathrm{CO}_{2}$ adsorption isotherms (obtained at $30{ }^{\circ} \mathrm{C}$ using a volumetric adsorption equipment ASAP 2000, Micromeritics) by the application of the Dubinin-Astakhov model. The average adsorbent crystal radius was determined from the scanning electron micrographs given in our previous study [66].

Prior to the CPC experiments, $0.7020 \mathrm{~g}$ of NZ was packed into the column and activated in situ first increasing the oven temperature to $100{ }^{\circ} \mathrm{C}$ where it was kept for $2 \mathrm{~h}$, then to $400{ }^{\circ} \mathrm{C}$ at a heating rate of $1{ }^{\circ} \mathrm{C} / \mathrm{min}$ and kept at this temperature for $12 \mathrm{~h}$ under continuous helium flow of $50 \mathrm{~mL} / \mathrm{min}$. To avoid detector contamination, the column outlet was not connected to the detector during this period. At the end of the activation process, the column was connected to the TCD and the oven was cooled down to the adsorption temperature at a cooling rate of $1^{\circ} \mathrm{C} / \mathrm{min}$. Then the carrier gas flow rate was set to the desired value and passed through the column until the detector signal has reached a constant value. $0.25 \mathrm{~mL}$ pulse of NO (purity of $99.5 \%$, Linde Gas) at atmospheric pressure was introduced into the carrier gas via a 6-port gas sampling valve (Valco Instruments). Following reaching a constant detector signal, the flow rate was set to the next value and pulse injection was repeated. The column outlet stream composition was continuously measured and recorded as a function of time using a thermal conductivity detector (TCD) operating at $250{ }^{\circ} \mathrm{C}$ equipped with the gas chromatograph (6890N, Agilent Technologies). The column was fully contained in the oven of the gas chromatograph for accurate temperature control. The flow rate of the carrier gas was controlled by a calibrated mass flow controller (5850S, Brooks Instruments) and confirmed by a bubble meter at the column exit. The CPC experiments were performed at column temperatures of $30,40,60$ and $80{ }^{\circ} \mathrm{C}$, and carrier gas flow rates of $10,20,40$ and $60 \mathrm{~mL} / \mathrm{min}$.

At infinite dilution (in the Henry's Law region of the isotherm), the first moment of the response peak is directly related to the Henry's Law constant. The first moment was calculated from the response peak using,

Table 1

Characteristics of the adsorption bed and the adsorbent (NZ).

\begin{tabular}{ll}
\hline Adsorbent particle diameter range $(\mu \mathrm{m})$ & $75-150$ \\
Average adsorbent particle diameter, $d_{\mathrm{p}}(\mu \mathrm{m})$ & 108.74 \\
Particle porosity, $\varepsilon_{\mathrm{p}}$ & 0.292 \\
Particle bulk density, $\rho_{\text {bulk }}\left(\mathrm{g} / \mathrm{cm}^{3}\right)$ & 1.246 \\
Particle solid density, $\rho_{\text {solid }}\left(\mathrm{g} / \mathrm{cm}^{3}\right)$ & 2.330 \\
Average adsorbent crystal radius, $r_{\mathrm{c}}(\mu \mathrm{m})$ & 3 \\
Bed diameter, $d_{\text {bed }}(\mathrm{mm})$ & 5.33 \\
Bed length, $L(\mathrm{~mm})$ & 41.00 \\
Bed voidage, $\varepsilon_{\text {bed }}$ & 0.436 \\
\hline
\end{tabular}

$\mu=\frac{\int_{0}^{\infty} c t \mathrm{~d} t}{\int_{0}^{\infty} c \mathrm{~d} t}$

where $t$ is the time and $c$ is the NO concentration measured at the outlet of the bed. The experimentally determined first moment values were corrected for the dead time in the system using the empty column response curves. The net first moment is given by,

$\mu_{\text {net }}=\frac{L}{v}\left(\frac{1-\varepsilon_{\text {bed }}}{\varepsilon_{\text {bed }}}\right)\left(1-\varepsilon_{p}\right) K_{c}$

where $L$ is the bed length, $\varepsilon_{\text {bed }}$ is the bed voidage, $v$ is the interstitial carrier gas velocity, and $K_{\mathrm{c}}$ is the dimensionless adsorption equilibrium constant which is related to the dimensionless Henry's Law constant $(K)$ by $K_{\mathrm{c}}=\left(K-\varepsilon_{\mathrm{p}}\right) /\left(1-\varepsilon_{\mathrm{p}}\right)$.

Temperature dependence of the Henry's Law constant $(K)$ is given by the van't Hoff equation,

$K=K_{o} \exp \left(-\frac{\Delta U_{0}}{\mathrm{R} T}\right)$

where $T$ is the temperature, $\mathrm{R}$ is the gas constant, $\Delta U_{\mathrm{o}}$ is the difference in internal energy between adsorbed and gaseous states (change in internal energy), and $K_{0}$ is the pre-exponential factor. $K_{0}$ and $\Delta U_{0}$ are derived as the intercept and the slope of the van't Hoff plot, respectively. The value of the limiting heat of adsorption at low coverage $\left(\Delta H_{0}\right)$ can then be calculated as,

$\Delta U_{o}=\Delta H_{o}+\mathrm{RT}$

where $T$ is taken as the average mean of the experimental range.

The second moment of the response peak $\left(\sigma^{2}\right)$ can be calculated as,

$\sigma^{2}=\frac{\int_{0}^{\infty} c(t-\mu)^{2} \mathrm{~d} t}{\int_{0}^{\infty} c \mathrm{~d} t}$

The experimentally determined second moments were also corrected for the dead volume in the system.

Adsorption within biporous adsorbent particle occurs in a series of mass transfer steps: Diffusion of adsorbate molecules from bulk to the adsorbent particle surface through the external film layer around the particle, diffusion of adsorbate molecules in macropores between the crystals, and diffusion of adsorbate molecules in micropores (within the crystals) to adsorption sites by micropore (intracrystalline) diffusion. For a biporous adsorbent, under the conditions of low sorbate concentration, isothermal operation, axially dispersed plug flow regime in the adsorption bed, instantaneous equilibrium between the adsorbate containing carrier gas and adsorbent phases, and negligible pressure drop across the bed, the net second moment can be expressed as,

$$
\begin{aligned}
\frac{\sigma^{2}}{2 \mu^{2}}= & \frac{D_{\mathrm{L}}}{\nu L}+\frac{\varepsilon_{\text {bed }} v}{L\left(\varepsilon_{\text {bed }}-1\right)}\left[\frac{R_{\mathrm{p}}}{3 k_{f}}+\frac{R_{\mathrm{p}}^{2}}{15 \varepsilon_{\mathrm{p}} D_{\mathrm{p}}}\right. \\
& \left.+\frac{r_{\mathrm{c}}^{2}\left(K-\varepsilon_{\mathrm{p}}\right)}{15 K^{2} D_{\mathrm{c}}}\right]\left[1+\frac{\varepsilon_{\text {bed }}}{\left(1-\varepsilon_{\text {bed }}\right) K}\right]^{-2}
\end{aligned}
$$

where $D_{\mathrm{L}}$ is the axial dispersion coefficient, $R_{\mathrm{p}}$ is the average adsorbent particle radius, $r_{\mathrm{c}}$ is the adsorbent crystal radius, $\varepsilon_{\mathrm{p}}$ is the particle porosity, $D_{\mathrm{p}}$ is the macropore diffusion coefficient, $D_{\mathrm{c}}$ is the 
intracrystalline (micropore) diffusion coefficient, and $k_{\mathrm{f}}$ is the external film mass transfer coefficient [67].

For gas adsorption systems, the value of $K$ is generally high hence $\varepsilon_{\text {bed }} /\left[\left(1-\varepsilon_{\text {bed }}\right) K\right]$ is small. This yields $\left(K-\varepsilon_{\mathrm{p}}\right) / K^{2} \approx 1 / K$ and Eq. (6) becomes,

$$
\frac{\sigma^{2} L}{2 \mu^{2} \nu}=\frac{D_{\mathrm{L}}}{\nu^{2}}+\frac{\varepsilon_{\text {bed }}}{\varepsilon_{\text {bed }}-1}\left(\frac{R_{\mathrm{p}}}{3 k_{f}}+\frac{R_{\mathrm{p}}^{2}}{15 \varepsilon_{\mathrm{p}} D_{\mathrm{p}}}+\frac{r_{\mathrm{c}}^{2}}{15 K D_{\mathrm{c}}}\right)
$$

The first term on the right-hand side of this equation represents the axial dispersion. The last term in parenthesis represents the sum of mass transfer resistances that exist for adsorption to take place in a column, packed with biporous adsorbent particles that are composed of zeolite crystals. The terms in the parentheses are external film mass transfer, macropore diffusion and micropore diffusion resistances, respectively.

The external film resistance is generally correlated in terms of dimensionless numbers of the type,

$S h=2 k_{f} R_{p} / D_{m}=f(R e, S c)$

where $S h, \operatorname{Re}\left(2 \rho_{\text {gas }} v \varepsilon_{\text {bed }} R_{\mathrm{p}} / \mu_{\text {gas }}\right)$ and $S c\left(\mu_{\text {gas }} / \rho_{\text {gas }} D_{\mathrm{m}}\right)$ are the Sherwood, Reynolds and Schmidt numbers, respectively, and $D_{\mathrm{m}}$ is the molecular diffusion coefficient. $\mu_{\text {gas }}$ and $\rho_{\text {gas }}$ are dynamic viscosity and density of the carrier gas, respectively.

For an isolated spherical adsorbent particle at low fluid velocities, $S h \approx 2$, hence $k_{\mathrm{f}}$ becomes,

$k_{f}=D_{m} / R_{p}$

Substituting in Eq. (7) gives,

$\frac{\sigma^{2} L}{2 \mu^{2} \nu}=\frac{D_{\mathrm{L}}}{\nu^{2}}+\frac{\varepsilon_{\text {bed }}}{\varepsilon_{\text {bed }}-1}\left(\frac{R_{p}^{2}}{3 D_{m}}+\frac{R_{\mathrm{p}}^{2}}{15 \varepsilon_{\mathrm{p}} D_{\mathrm{p}}}+\frac{r_{c}^{2}}{15 K D_{\mathrm{c}}}\right)$

The contributions from mass transfer resistances and axial dispersion to the peak broadening can be separated by measurements over a range of carrier gas velocities. Eq. (10) suggests that a plot of the dispersion $\left(\sigma^{2} L / 2 \mu^{2} v\right)$ vs $1 / v^{2}$ should be approximately linear with slope $D_{\mathrm{L}}$ and intercept given by the last term on the right-hand side of Eq. (10). Consequently, the micropore diffusion resistance is calculated by subtracting the contributions of the external film and macropore diffusion resistances from the total mass transfer resistance. Reliable values for the micropore diffusion coefficient can only be obtained when it is the dominant mass transfer mechanism.

Contributions from the external film and macropore diffusion resistances can be estimated using the correlations given in the literature. The molecular diffusion coefficient $\left(D_{\mathrm{m}}\right)$ can be estimated by Refs. [68],

$D_{m}=0.0018583 T^{3 / 2} \frac{\left(1 / M_{A}+1 / M_{B}\right)^{1 / 2}}{P \sigma_{A B}^{2} \Omega_{A B}}$

where $T$ is the temperature, $M$ is the molecular weight, $P$ is the total pressure, $\sigma$ is the collision diameter of the diffusing molecules, and $\Omega$ is the collision integral.

In macropores, diffusion occurs through Knudsen and molecular diffusion. Relative importance of molecular or Knudsen diffusion is largely determined by the average macropore diameter. Molecular diffusion is the dominant mechanism if the mean free path of the gas molecule is smaller than the average macropore diameter. The Knudsen diffusion becomes the mass transfer controlling mechanism if the mean free path is larger than the pore diameter. Knudsen diffusion coefficient $\left(D_{\mathrm{K}}\right)$ can be estimated from Refs. [69],

$D_{K}=9700 r_{p} \sqrt{\frac{T}{M}}$

where $r_{\mathrm{p}}$ is the average macropore radius, $M$ is the molecular weight, and $T$ is temperature.

If the pore diameter is comparable to the mean free path the macropore diffusion coefficient $\left(D_{\mathrm{p}}\right)$ is given by a combination of molecular diffusion and Knudsen diffusivity, and can be estimated by,

$\frac{1}{D_{p}}=\tau\left(\frac{1}{D_{m}}+\frac{1}{D_{K}}\right)$

where $\tau$ is tortuosity factor. Experimental tortuosity factors generally fall within the range 2-6 [67].

From a comparison of the mass transfer resistances measured under different experimental conditions, it is possible to establish which mass transfer resistance is dominant. Having predicted the macropore diffusion coefficient from Eq. (13), the micropore diffusion resistance can be calculated from Eq. (10). Consequently the micropore diffusion coefficient $\left(D_{\mathrm{c}}\right)$ values are calculated. From the temperature dependence of $D_{\mathrm{c}}$ by the Arrhenius type equation,

$\frac{D_{c}}{r_{c}^{2}}=\frac{D_{o}}{r_{c}^{2}} \exp \left(-\frac{E_{a}}{R T}\right)$

the activation energy for micropore diffusion $\left(E_{\mathrm{a}}\right)$ can be calculated. Here $D_{0}$ represents the limiting micropore diffusion coefficient.

\subsection{Temperature-programmed desorption (TPD)}

To investigate reversibility of the NO adsorption, the adsorbent was saturated with $0.25 \mathrm{~mL}$ pulses of $\mathrm{NO}$ to $10 \mathrm{~mL} / \mathrm{min}$ carrier gas flow at $30^{\circ} \mathrm{C}$, the bed was then purged with helium flow of $20 \mathrm{~mL} /$ min at $30{ }^{\circ} \mathrm{C}$ until the detector signal has reached the baseline. Purpose of this purging step was to remove the gas-phase and reversibly adsorbed NO species.

Temperature-programmed desorption (TPD) experiments were performed by ramping the oven temperature to its maximum temperature of $400{ }^{\circ} \mathrm{C}$ at a rate of $1{ }^{\circ} \mathrm{C} / \mathrm{min}$ and keeping at this temperature for $180 \mathrm{~min}$ under helium flow of $20 \mathrm{~mL} / \mathrm{min}$. During the purging and TPD, the column outlet gas was monitored continuously by the TCD.

\section{Results and discussion}

\subsection{Concentration pulse chromatography (CPC)}

The chromatographic response peaks obtained for the empty column were symmetric, while tailed peaks were obtained from the packed bed experiments. The chromatographic response peaks to the NO pulses obtained under different experimental conditions were processed to determine the first and second moments. Linear relationships were obtained between the empty column first moment and the superficial carrier gas velocity at the adsorption temperatures with identical slopes. For the packed column, fairly linear relationships $\left(r^{2} \geq 0.994\right)$ were obtained between the net first moment $\left(\mu_{n e t}\right)$ and the reciprocal of the interstitial carrier gas velocity at different temperatures (Fig. 2). The linear relationship verified that the equilibrium has been reached in the column and the pulse volume injected falls in the linear region of the adsorption isotherms. 


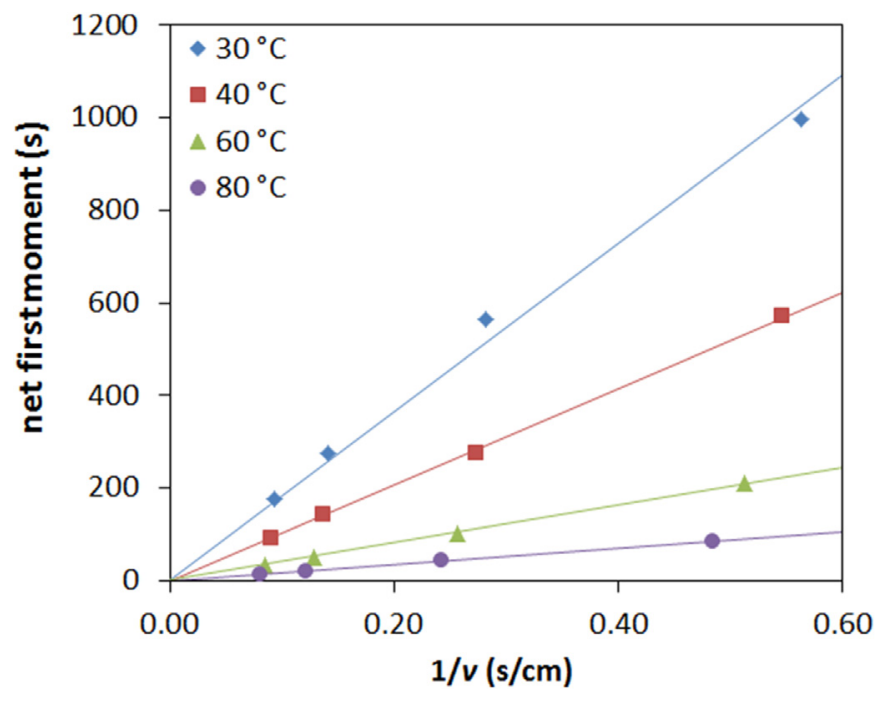

Fig. 2. Net first moment versus the reciprocal of the interstitial carrier gas velocity at different temperatures.

The Henry's Law constants $(K)$ calculated from the slopes of these plots were in the range of 33.37-343.97. Dependence of the Henry Law constant on temperature is shown in Fig. 3. The limiting heat of adsorption and $K_{0}$ values were calculated from Eqs. (3) and (4) and given in Table 2. The values given in the literature for the other natural zeolitic materials are shown in the same table. It can be seen that the heat of adsorption determined in the present study is higher than that reported in the literature for another natural zeolitic material from other deposit in Turkey. The higher Henry's Law constants indicated stronger interaction between NO and the adsorbent. It is known that electrostatic interactions between a polar molecule such as NO and extraframework cations depend on the cation content of the adsorbent.

At low equilibrium pressures (in the Henry's Law region), interactions between a polar adsorbate molecule and adsorbent surface occur through electrostatic interactions between quadrupole moment of the polar adsorbate and the zeolite cations. The strength of such interaction depends mainly on the overall intensity of local electrostatic field originating from the ionic nature

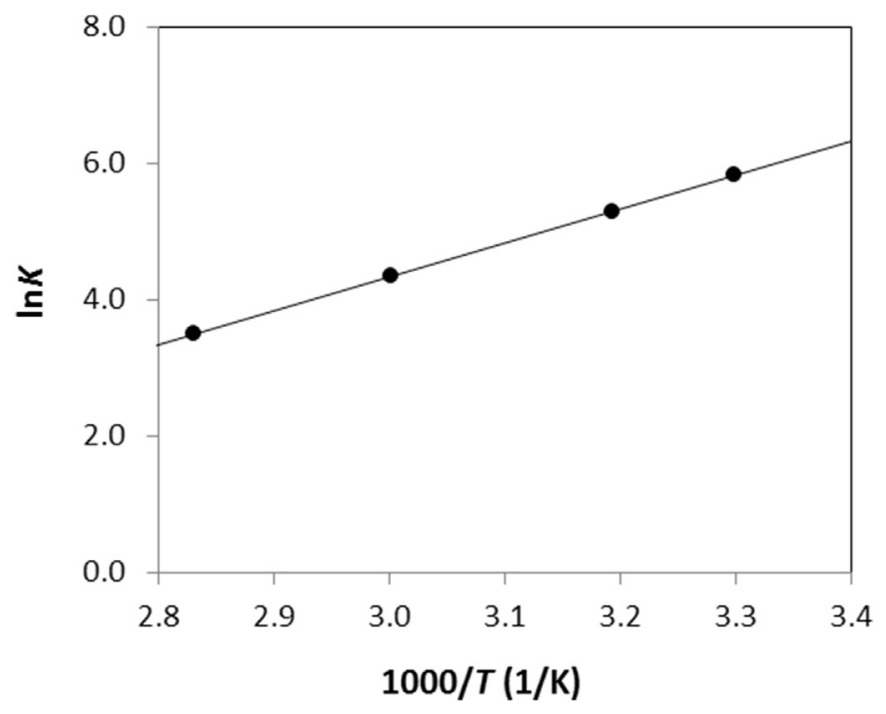

Fig. 3. Van't Hoff plot. of the adsorbent framework and on the polarity (dipole and quadrupole moments) and/or polarizability of the adsorbate molecules [70]. NZ has a higher Si/Al ratio (5.21) than that for another zeolitic material from a different deposit in Turkey (Bigadiç) (reported as 4.25) [59]. The amount of extraframework cations present in a zeolite depends on the Si/Al ratio of the zeolite: As the Si/Al ratio decreases, there are more $\mathrm{Al}$ atoms in the structure and hence a greater cationic density of the zeolite [71]. The lower extraframework cation content results in a less interaction with a polar adsorbate molecule. On the other hand not only the amount but also the type of cation (valence, size etc.) influences the interactions with the adsorbate. $\mathrm{NZ}$ contains mainly $\mathrm{K}_{2} \mathrm{O}(5.12 \mathrm{wt} \%)$ followed by $\mathrm{Na}_{2} \mathrm{O}$ (1.85 wt \%), $\mathrm{CaO}$ (1.49 wt \%), and $\mathrm{MgO}$ (0.44 wt \%) as well as $\mathrm{Fe}_{2} \mathrm{O}_{3}$ (1.49 wt \%) [66]. For the other zeolitic material from Turkey (Bigadiç) the major cations were reported as $\mathrm{Ca}^{2+}(2.87 \mathrm{wt} \% \mathrm{CaO})$ and $\mathrm{K}^{+}\left(2.41 \mathrm{wt} \% \mathrm{~K}_{2} \mathrm{O}\right)$, followed by $\mathrm{Mg}^{2+}(1.99 \mathrm{wt} \% \mathrm{MgO})$, a small amount of $\mathrm{Na}^{+}\left(0.32\right.$ wt \% $\left.\mathrm{Na}_{2} \mathrm{O}\right)$ and some $\mathrm{Fe}_{2} \mathrm{O}_{3}$ (1.27 wt \%) [72].

In another study the isosteric heat of $\mathrm{NO}$ adsorption for clinoptilolite from Mexico were determined from the adsorption isotherms at $0{ }^{\circ} \mathrm{C}$ and $20^{\circ} \mathrm{C}$ as decreasing from 37.2 to $16.3 \mathrm{~kJ} / \mathrm{mol}$ for the NO loadings from zero to $0.7 \mathrm{mmol} / \mathrm{g}$, respectively. The loading dependence of the isosteric heat of adsorption reflects the adsorbent surface heterogeneity [55]. The isosteric heat of adsorption at zero NO loading reported was lower than the limiting heat of adsorption determined in the present study. The higher isosteric heat at low adsorbate loadings reveals stronger adsorbateadsorbent interactions.

Explanation of differences in Henry's Law constant and limiting heat of adsorption values for different natural zeolitic materials by the cation content is valid if $\mathrm{NO}$ is adsorbed in the micropores of clinoptilolite (the microporous constituent of the natural zeolitic material). Otherwise the mineral composition of the zeolitic material should be taken into account. Since natural zeolitic materials contain other mineral phases beside zeolite, their zeolite content also determines their adsorption characteristics [73].

The isosteric heats of NO adsorption were reported as $27.6 \mathrm{~kJ} /$ mol for Na-mordenite [31], as $23.5 \mathrm{~kJ} / \mathrm{mol}$ for H-mordenite, $18.4 \mathrm{~kJ} /$ mol for H-ZSM-5 [33], 42-63 kJ/mol for Mg-mordenite, 38-42 kJ/ mol for Ca-mordenite, $33 \mathrm{~kJ} / \mathrm{mol}$ for Ba-mordenite [34] at the coverage of $0.02,46.3 \mathrm{~kJ} / \mathrm{mol}$ for mordenite at zero coverage [55], $37.3 \mathrm{~kJ} / \mathrm{mol}$ for 5 A pellets, $9.2 \mathrm{~kJ} / \mathrm{mol}$ for $13 \mathrm{X}$ pellets and $20.1 \mathrm{~kJ} / \mathrm{mol}$ for natural mordenite extrudates by gas chromatography [62].

The plots of total dispersion $\left(\sigma^{2} L / 2 \mu^{2} v\right)$ versus $1 / v^{2}$ are shown in Fig. 4. The plots were fairly linear $\left(r^{2} \geq 0.918\right)$ with slope of $D_{\mathrm{L}}$ and intercept given by the last term in Eq. (10). Such plots provide a convenient means of distinguishing the mass transfer resistances that the adsorbate molecules encounter during the adsorption.

The estimated values for $D_{\mathrm{m}}, D_{\mathrm{K}}$ and $D_{\mathrm{p}}$ are reported in Table 3 together with the dimensionless numbers and the pressure drop. In calculation of $D_{\mathrm{K}}$ (Eq. (12)), the average macropore radius $\left(r_{\mathrm{p}}\right)$ value of $3.063 \mathrm{~nm}$ which was determined from the $\mathrm{N}_{2}$ desorption isotherm at $-196^{\circ} \mathrm{C}$ by the application of the $\mathrm{BJH}$ method was used. The particle tortuosity value of 6 was used in the calculation of $D_{\mathrm{p}}$ in order to maximize the contribution from the macropore diffusion to the total resistance. Axial dispersion occurs due to contributions from molecular diffusion in the interparticle void spaces and turbulent mixing due to the splitting and recombination of flows around the adsorbent particles. The ScRe values lower than 10 indicated dominance of molecular diffusion in axial dispersion and $D_{L}$ is independent of velocity as $R e<100$ [74]. The pressure drop across the bed calculated using the Ergun equation was in the range of $0.003-0.019$ bar and assumed to be negligible.

The contributions from different mass transfer resistances to the total mass transfer resistance are given in Table 4 . The external film mass transfer $\left(R_{\mathrm{p}}^{2} / 3 D_{m}\right)$, and macropore diffusion resistances $\left(R_{\mathrm{p}}^{2} /\right.$ 
Table 2

Heat of adsorption and pre-exponential factor values for NO.

\begin{tabular}{|c|c|c|c|c|c|}
\hline Adsorbent (deposit) & $T\left({ }^{\circ} \mathrm{C}\right)$ & $K_{\mathrm{o}}$ (dimensionless) & $-\Delta H_{\mathrm{o}}(\mathrm{kJ} / \mathrm{mol})$ & Method & Reference \\
\hline Clinoptilolite (Gördes, Turkey) & $30-80$ & $2.52 \times 10^{-5}$ & 44.1 & \multirow[t]{2}{*}{ Gas chromatography } & \multirow{3}{*}{$\begin{array}{l}\text { Present study } \\
{[59]} \\
{[55]}\end{array}$} \\
\hline Clinoptilolite (Bigadiç, Turkey) & $100-200$ & $6.30 \times 10^{-4}$ & 39.4 & & \\
\hline Clinoptilolite (Mexico) & 0,20 & - & 37.2 & Volumetric & \\
\hline
\end{tabular}

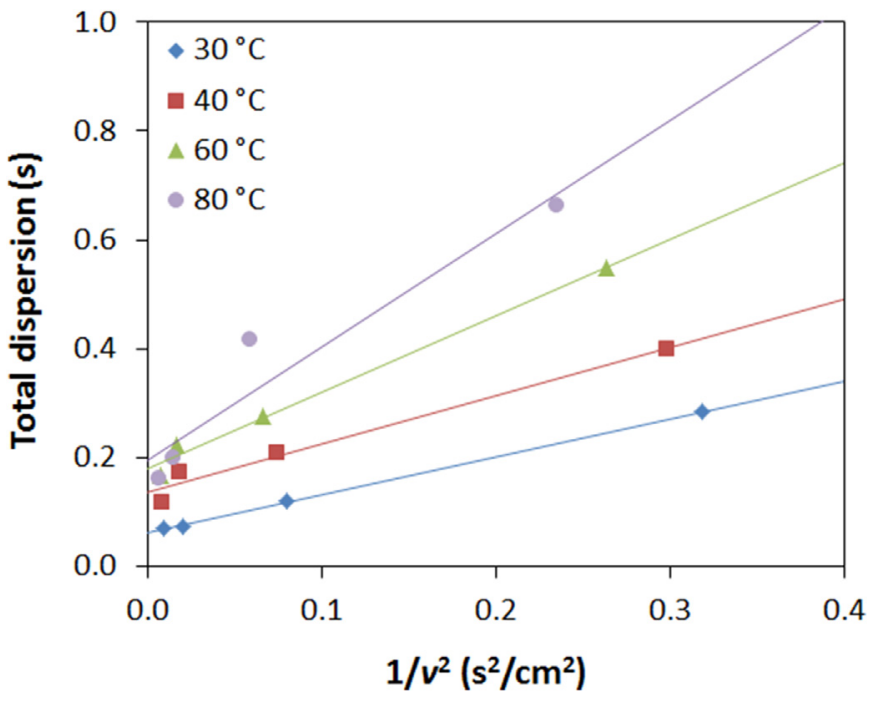

Fig. 4. Plots of total dispersion $\left(\sigma^{2} L / 2 \mu^{2} v\right)$ vs $1 / v^{2}$.

Table 3

The estimated values of the diffusion coefficients and dimensionless numbers

\begin{tabular}{llllll}
\hline$T\left({ }^{\circ} \mathrm{C}\right)$ & $D_{\mathrm{K}}\left(\mathrm{cm}^{2} / \mathrm{s}\right)$ & $D_{\mathrm{m}}\left(\mathrm{cm}^{2} / \mathrm{s}\right)$ & $D_{\mathrm{p}}\left(\mathrm{cm}^{2} / \mathrm{s}\right)$ & $R e$ & $S c$ \\
\hline 30 & $9.44 \times 10^{-3}$ & 0.7400 & $1.55 \times 10^{-3}$ & $0.007-0.071$ & $1.14-1.52$ \\
40 & $9.60 \times 10^{-3}$ & 0.7812 & $1.58 \times 10^{-3}$ & & \\
60 & $9.90 \times 10^{-3}$ & 0.8668 & $1.63 \times 10^{-3}$ & & \\
80 & $1.02 \times 10^{-2}$ & 0.9567 & $1.68 \times 10^{-3}$ & & \\
\hline
\end{tabular}

$\left.15 \varepsilon_{\mathrm{p}} D_{\mathrm{p}}\right)$ were estimated through Eqs. $11-13$ and the micropore diffusion resistance $\left(r_{\mathrm{c}}^{2} / 15 K D_{\mathrm{c}}\right)$ was calculated by subtracting the sum of the external film and macropore diffusion resistances from the total mass transfer resistance, intercept $\times\left(1-\varepsilon_{\text {bed }}\right) / \varepsilon_{\text {bed }}$, according to Eq. (10). From Table 4, it can be seen that the contributions from external film mass transfer and macropore diffusion resistances are negligible as compared to that from the micropore diffusion (with more than $94.6 \%$ of the total resistance) being the dominant mass transfer mechanism for NO adsorption in NZ. Relative importance of internal and external mass transfer resistances can be determined by the Biot number $\left(B i=S h D_{\mathrm{m}} / 6 \varepsilon_{\mathrm{p}} D_{\mathrm{e}}\right)$ where $D_{\mathrm{e}}$ is the effective intraparticle diffusion coefficient. The criterion for negligible external mass transfer resistance is given as $B i>20$ [67]. The calculated $B i$ numbers in the present study were

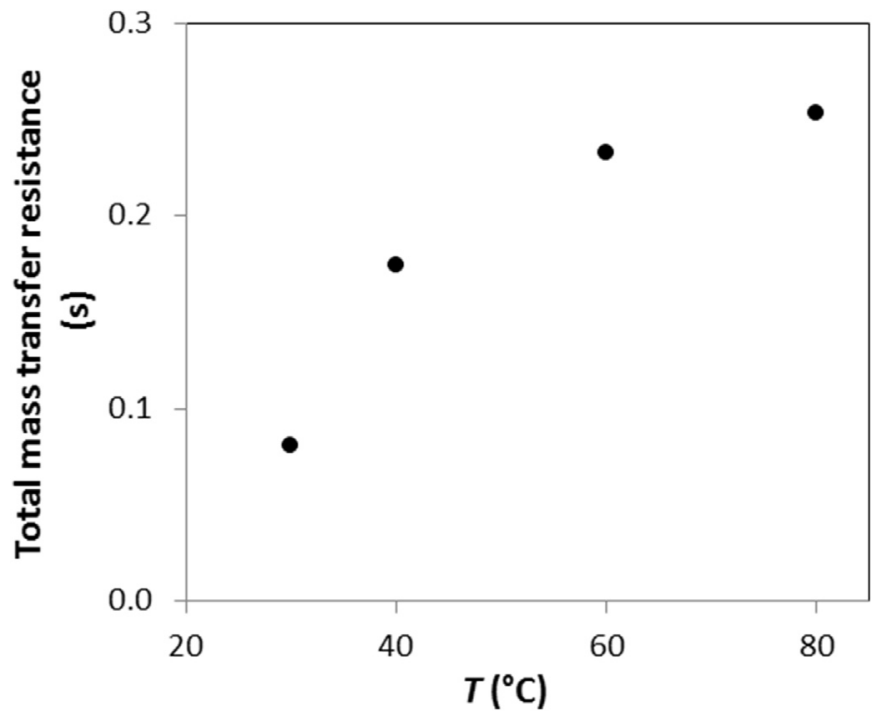

Fig. 5. Temperature dependence of the total mass transfer resistance.

above 70 clearly implying control of the intraparticle diffusion in the NO adsorption in NZ.

The total mass transfer resistance increased with the bed temperature as shown in Fig. 5 also indicating dominance of the micropore diffusion in NO adsorption since the only strongly temperature-dependent resistance on the right hand side of Eq. (10) is micropore diffusion.

From the temperature dependence of the micropore diffusion coefficient $\left(D_{\mathrm{c}}\right)$ given by Eq. (14), the activation energy for micropore diffusion $\left(E_{\mathrm{a}}\right)$ was calculated from the slopes of semi-log plots of $D_{\mathrm{c}} / r_{\mathrm{c}}^{2}$ (micropore diffusion time constant) versus the reciprocal of the temperature (Fig. 6) and reported in Table 5.

The high activation energy for micropore diffusion reflects a high kinetic barrier to diffusion. This is expected in our case since the kinetic diameter of NO molecules (3.17 А, [59]) is close to the channel dimensions of the clinoptilolite. Micropore diffusion is an activated process and the temperature dependence can generally be correlated according to Eq. (14). In small-pore zeolites in which the free aperture of the window is only slightly greater than the critical diameter of the adsorbate molecule, the activation energy correlates directly with critical molecular diameter suggesting that the rate-limiting step is the passage of the adsorbate molecule through the zeolite windows [67]. Furthermore diffusion of

Table 4

Mass transfer resistances and their contribution to the total mass transfer resistance (\%).

\begin{tabular}{|c|c|c|c|c|c|c|c|}
\hline \multirow[t]{2}{*}{$T\left({ }^{\circ} \mathrm{C}\right)$} & \multicolumn{4}{|c|}{ Mass transfer resistances (s) } & \multicolumn{3}{|c|}{ Contribution to total mass transfer resistance (\%) } \\
\hline & Total & External film, $R_{\mathrm{p}}^{2} / 3 D_{m}$ & Macropore diffusion, $R_{\mathrm{p}}^{2} / 15 \varepsilon_{\mathrm{p}} D_{\mathrm{p}}$ & Micropore diffusion, $r_{\mathrm{c}}^{2} / 15 K D_{\mathrm{c}}$ & External film & Macropore diffusion & Micropore diffusion \\
\hline 30 & 0.081 & $1.33 \times 10^{-5}$ & $4.34 \times 10^{-3}$ & 0.076 & 0.0017 & 5.37 & 94.62 \\
\hline 40 & 0.174 & $1.26 \times 10^{-5}$ & $4.27 \times 10^{-3}$ & 0.170 & 0.0072 & 2.45 & 97.55 \\
\hline 60 & 0.233 & $1.14 \times 10^{-5}$ & $4.13 \times 10^{-3}$ & 0.228 & 0.0049 & 1.78 & 98.22 \\
\hline 80 & 0.253 & $1.03 \times 10^{-5}$ & $4.01 \times 10^{-3}$ & 0.249 & 0.0041 & 1.58 & 98.41 \\
\hline
\end{tabular}




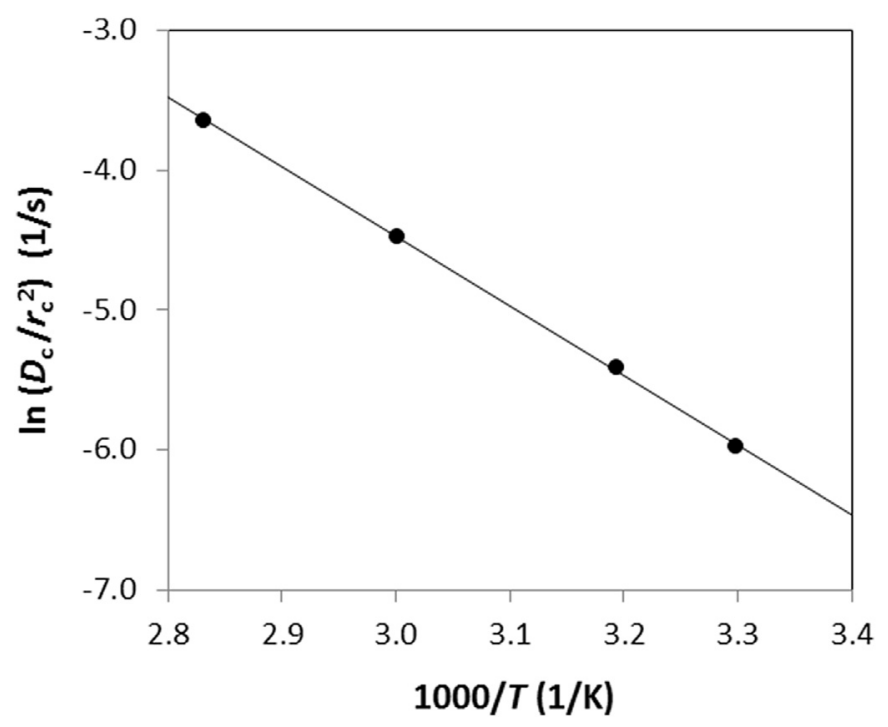

Fig. 6. Dependence of $D_{\mathrm{c}} / r_{\mathrm{c}}^{2}$ on temperature.

molecules in such small pores is very restricted because of the effect of potential field of the wall atoms. Adsorbate molecules in the micropores are considered to be on the adsorption sites. These molecules move from site to site across the potential energy barrier [74]. In such diffusion, the interactions between the cations in the cages and the gas molecules play an important role [62]. The contributions of the framework and extraframework cations and adsorbate molecules to these internal fields are all important and interdependent [75]. It was reported that changing the cations in a zeolite, the pore openings can be effectively modified as a result of change in the cation population and/or a relocation of cations [71]. As a consequence, the discrepancies in the activation energies for micropore diffusion for clinoptilolite-rich natural zeolitic materials from different deposits can be explained by differences in the types, locations and amounts of the cations present in the micropores. Furthermore adsorption capacity and selectivity of a zeolite are dependent on its dehydration level. The activation process employed prior to the adsorption can result in migration of the cations, hence the cation locations and pore openings change so the diffusion rate [50]. Hernández-Huesca et al. activated the clinoptilolite at $300{ }^{\circ} \mathrm{C}$ in an oven constantly evacuating up to a residual pressure of $10^{-3}$ Torr and keeping under these conditions for $3 \mathrm{~h}$ prior to the NO adsorption [54] which is different from the activation procedure employed in the present study. Significant influence of the regeneration procedure on the uptake rate and diffusion coefficient has been reported in the literature [76-78]. Even the controlling resistance might change from intraparticle diffusion to surface resistance control depending on the activation conditions [76].

The log-log plot of reciprocal micropore diffusion time constant $\left(D_{\mathrm{c}} / r_{\mathrm{c}}^{2}\right)$ versus Henry's Law constant is shown in Fig. 7. This trend can be interpreted as stronger adsorption results in larger activation energy of jump and consequently slower diffusion.

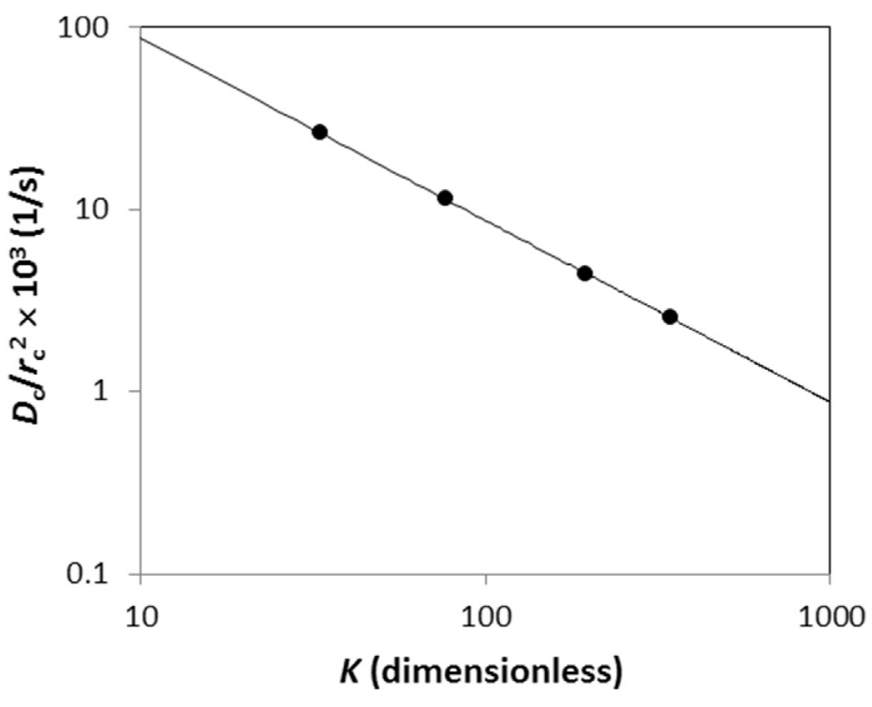

Fig. 7. Plot of $D_{c} / r_{c}^{2}$ versus $K$.

Similar relationship between $D_{c} / r_{c}^{2}$ versus $K$ was recently given in the literature for BPL activated carbon and 13X zeolite [79] and for a metal organic framework (UTSA-16) [80] for adsorption of $\mathrm{N}_{2}$, $\mathrm{CO}, \mathrm{CO}_{2}$ and $\mathrm{CH}_{4}$ gases. This correlation was suggested for rough estimation of the reciprocal diffusion time constant of a given gas by estimating the $K$ value only. Linear relations were obtained between activation energies of diffusion in micropore and isosteric heats of adsorption for several gases for molecular sieve carbons by Chihara et al. [81].

In the pores for which the diameter is comparable to that of the diffusing molecule, the diffusing molecules cannot escape from the force field of the pore walls. In this pore region diffusion occurs by an activated process in which the molecules jump randomly between neighboring low energy sites. This diffusion regime is referred as configurational diffusion, activated diffusion or zeolitic diffusion. The micropore diffusivity changes considerably with the molecular dimensions of the sorbate molecule and the free dimensions of the channels. The geometry of the pores, chemical composition of the zeolite (type, charge and distribution of the cations), shape, size, polarity and concentration of the diffusing molecules, and temperature strongly affect diffusion in the micropores. Micropore diffusion is sensitive to the complete or partial blockage of the certain channels [77].

The slow adsorption of NO observed for clinoptilolite from Mexico was explained by the formation of NO dimers $\left(\mathrm{N}_{2} \mathrm{O}_{2}\right)$ inside the micropores, blocking the diffusion of further NO molecules into the same pores [55]. Formation of NO dimers was also reported in the literature for LTA zeolite [82], sodium mordenite [31] and ironmodified activated carbon fibers [83,84].

Ma and Mancel explained the higher diffusional resistances for NO in the natural mordenite as compared to $13 \mathrm{X}$ and $5 \mathrm{~A}$ by the increased ease of flow in the three-dimensional network of $13 \mathrm{X}$ and $5 \mathrm{~A}$. The larger diffusion coefficient for $\mathrm{NO}$ in $13 \mathrm{X}$ pellets

Table 5

$D_{\mathrm{o}} / r_{\mathrm{c}}^{2}$ and $E_{\mathrm{a}}$ values for micropore diffusion of NO.

\begin{tabular}{|c|c|c|c|c|c|}
\hline Adsorbent (deposit) & $T\left({ }^{\circ} \mathrm{C}\right)$ & $D_{\mathrm{o}} / r_{\mathrm{c}}^{2}(1 / \mathrm{s})$ & $E_{\mathrm{a}}(\mathrm{kJ} / \mathrm{mol})$ & Method & Reference \\
\hline Clinoptilolite (Gördes, Turkey) & $30-120$ & $34,574.6$ & 41.4 & Chromatographic & Present study \\
\hline Clinoptilolite (Mexico) & 0,20 & - & 19 & Volumetric & {$[54]$} \\
\hline Erionite & & - & 24 & & \\
\hline Mordenite & & - & 9 & & \\
\hline
\end{tabular}


$\left(7.1 \times 10^{-2} \mathrm{~cm}^{2} / \mathrm{s}\right.$ at $\left.261^{\circ} \mathrm{C}\right)$ than in 5 A pellets $\left(2.29 \times 10^{-2} \mathrm{~cm}^{2} / \mathrm{s}\right.$ at $261{ }^{\circ} \mathrm{C}$ ) was attributed to the large openings of the faujasite type cages. The much lower diffusion coefficient for the natural mordenite extrudates $\left(0.72 \times 10^{-2} \mathrm{~cm}^{2} / \mathrm{s}\right.$ at $\left.261{ }^{\circ} \mathrm{C}\right)$ was explained by the different pore systems for diffusion: one-dimensional for mordenites as compared with three-dimensional for $5 \mathrm{~A}$ and $13 \mathrm{X}$ sieves. It must be noted that these diffusion coefficients are the overall effective diffusion coefficient which includes the contribution from both the micropores and macropores. The activation energies for diffusion of NO were reported as 17.6, 79.5, and $34.3 \mathrm{~kJ} /$ mol for $13 \mathrm{X}, 5 \mathrm{~A}$ pellets, and natural mordenite extrudates, respectively. The high activation energy is associated with high isosteric heat of adsorption [62].

In considering kinetic separation diffusion processes the value of $D_{\mathrm{c}} / r_{\mathrm{c}}^{2}$ can be used to calculate the kinetic separation factor, which is useful in predicting promising separation conditions.

For an adsorbent to be used in a cyclic adsorption/separation process, it should have high reversible adsorption capacity and high selectivity. Therefore besides the adsorption equilibrium and kinetic properties the reversibility of the adsorption is important.

The irreversibility of the NO adsorption was examined through successive NO pulse injections to the column without heat treatment or evacuation before the pulses. Variation of the retention time and area of the response peaks with the injection number is shown in Fig. 8. The retention time of the response peak decreased with the injection number while the area increased implying the irreversibility of the NO adsorption. NZ adsorbed less NO than the previous injection for the first 80 injections. For further injections the response peak area did not change probably indicating saturation of the strong adsorption sites. In the literature decrease in the retention time and areas of the response peaks with the injection number was reported for NO adsorption in commercial $5 \mathrm{~A}$ pellets [61]. The irreversibility of NO adsorption in NZ was also reported in our previous study based on the adsorption and desorption breakthrough curves [66].

Irreversibility of NO adsorption was reported in the literature for clinoptilolite from Mexico. Contribution from irreversible NO adsorption on this clinoptilolite was found to be dependent on the NO pressure and varied in the range of $49-57 \%$ of the total adsorption. The irreversibility was explained by formation of dimeric NO complexes in the micropores which could not be evacuated from the micropores at $20{ }^{\circ} \mathrm{C}[54,55]$. Reversibly and

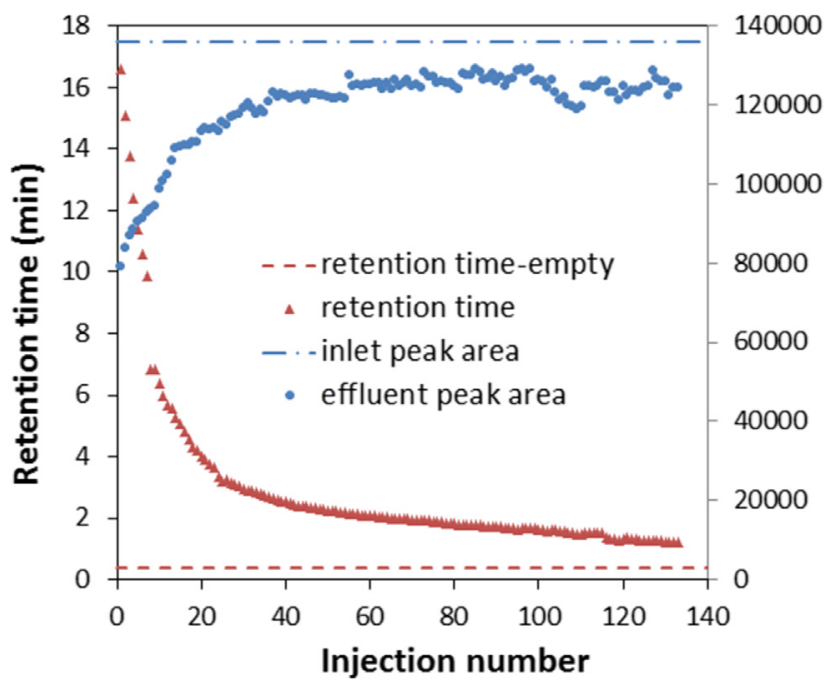

Fig. 8. Variation of the effluent peak area and retention time with the successive injections of NO pulses at $30^{\circ} \mathrm{C}$. irreversibly adsorbed amounts of NO greatly change with the type of exchanged metal (transition, alkaline earth, alkali or earth metals) and with the zeolite topology. For alkaline earth metalexchanged MFI zeolites higher reversible NO adsorption capacities than the irreversible one were previously reported [37].

\subsection{Temperature-programmed desorption}

After the adsorbent was saturated with the NO pulses, the bed was purged with pure helium at $20 \mathrm{~mL} / \mathrm{min}$ flow rate at $30^{\circ} \mathrm{C}$ in order to remove the gas-phase and reversibly adsorbed NO. During this purging step, the detector signal decreased continuously and reached the baseline after $4 \mathrm{~h}$. After that the oven temperature has started to be increased to $400{ }^{\circ} \mathrm{C}$ at a rate of $1{ }^{\circ} \mathrm{C} / \mathrm{min}$. The composition of the column outlet stream was continuously monitored by the thermal conductivity detector. The TPD profile recorded is shown in Fig. 9. Since the weakly adsorbed NO species were removed by the helium purge at $30^{\circ} \mathrm{C}$, the peaks detected in the TPD profile were indication of strongly adsorbed NO species. Desorption of these species has started at temperatures as low as $30{ }^{\circ} \mathrm{C}$ and has not been completed at $400{ }^{\circ} \mathrm{C}$. Two symmetrical peaks were detected at 80 and $240{ }^{\circ} \mathrm{C}$ in the TPD profile. Another species has started to desorb around $294^{\circ} \mathrm{C}$, but the desorption has not been completed since the temperature increase has been terminated. The multiple peaks implied presence of distinct adsorption sites for NO and formation of species with different thermal stabilities.

As the temperature increases, particularly adsorbed species are detected as a peak in the TPD profile. Presence or absence of desorption peaks in a TPD profile can also be interpreted in terms of accessibility of the active sites to NO molecules. Area of the peak is related to the concentration of the desorbed species. The area of the second peak was less than the first peak that is most of the strongly adsorbed species desorbed below $120{ }^{\circ} \mathrm{C}$.

In our previous study, transmittance IR spectra for NZ after saturation with NO, the purging and TPD were reported [66]. A sharp and intense band detected at $1385 \mathrm{~cm}^{-1}$ in the transmission spectrum of the NO loaded NZ lost intensity appreciably after heating to $400{ }^{\circ} \mathrm{C}$ under helium flow. Upon contact with water, the NO loaded NZ exhibited antibacterial activity due to release of the irreversibly adsorbed NO. The $1385 \mathrm{~cm}^{-1}$ band was assigned to nitrate species and formation of the nitrate species in the absence

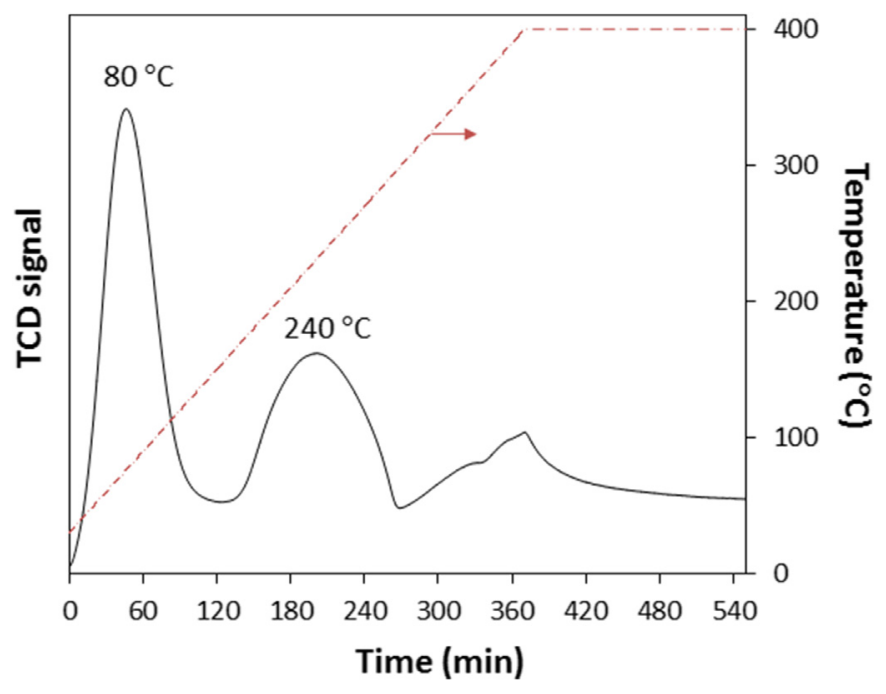

Fig. 9. TPD profile for NZ. 
Table 6

Calculated activation energies for desorption of the strongly adsorbed NO species detected in the TPD profile.

\begin{tabular}{lll}
\hline TPD peak & Desorption temperature, $T_{\mathrm{p}}\left({ }^{\circ} \mathrm{C}\right)$ & Activation energy for desorption, $E_{\mathrm{a}, \mathrm{des}}(\mathrm{kJ} / \mathrm{mol})$ \\
\hline 1st peak & 80 & 107.80 \\
2nd peak & 240 & 158.30 \\
\hline
\end{tabular}

of oxygen was explained by involvement of the lattice oxygen in the reaction [66].

NO is a strong Lewis base and, when it has a $\sigma$-bonded interaction it is more firmly adsorbed on cationic sites. Furthermore, due to an unpaired electron in the NO molecule, NO is adsorbed as dimers [85]. The NO coordination to the unsaturated metal cations in dehydrated zeolites is different from the physical adsorption since it involves electron transfer between them. It was stated that the NO interacts with the extraframework cations in zeolites through the nitrogen atom to form either mononitrosyl or dinitrosyl complexes [86]. Ivanova and co-workers reported that symmetric nitrates have formed on $\mathrm{NaY}$ upon $\mathrm{NO}$ adsorption that were stable up to around $400{ }^{\circ} \mathrm{C}$ [87].

The Redhead equation [88] was used to calculate the desorption energies of the different species observed in the TPD profile,

$\frac{E_{a, \mathrm{des}}}{\mathrm{R} T_{p}^{2}}=\frac{\eta}{\beta} \exp \left(-\frac{E_{a, \mathrm{des}}}{\mathrm{R} T_{p}}\right)$

where $E_{\mathrm{a} \text {,des }}$ is the activation energy for desorption, $T_{\mathrm{p}}$ is the temperature at which the desorption maximum occurs, $\eta$ is the preexponential factor and $\beta$ is the heating rate.

The desorption activation energies calculated using Eq. (15) with a pre-exponential factor of $10^{13} \mathrm{~s}^{-1}$ are given in Table 6 . Note that these calculations only give the approximate values as an assumption has been made that the desorption reaction is first order. Furthermore the Redhead equation assumes that the activation energy for desorption and the pre-exponential factor are coverage independent.

For the kinetic analysis from a single TPD curve, a simple method has been proposed by Konvalinka et al. [89] by applying the method originally developed by Kissinger [90] to determine the reaction order of thermal decompositions of solids. In this method, the desorption order $(n)$ can be determined from the shape index of the TPD peaks assuming a ratio of 1.08 between the temperature at the inflection points,

$n=1.26 S^{1 / 2}$

The shape index $(S)$ is defined as the ratio between the slopes of the tangents to the TPD curve at the inflection points. In the present study the orders of desorption reactions corresponding to the first and second peaks were calculated as 1.43 and 1.46 from Eq. (16), respectively.

The high desorption activation energies implied chemisorption of NO in NZ. For that reason NZ is not a suitable adsorbent for cyclic adsorption processes for NO separation where thermal swing desorption is employed due to high irreversibility of the adsorption. The high irreversibility dictates high energy requirement for desorption of the adsorbed NO species by thermal swing adsorption. Displacement of the adsorbed component from the saturated adsorbent by a desorbent which is more strongly adsorbed than the adsorbed component is another common regeneration method. The choice of desorbent is crucial to the success of such a process. If the desorbent is too strongly adsorbed it cannot be effectively displaced from the bed during the adsorption cycle, leading to very low utilization of adsorbent capacity or poor product recovery, while if the desorbent is too weakly adsorbed, a very large desorbent flow rate and a long desorption period are required in order to desorb the adsorbed product during the regeneration cycle [67]. In the case of NO adsorption, the adsorbed NO can be displaced by water molecules which have higher affinity for NZ.

Displacement of the irreversibly adsorbed NO from the metalexchanged A zeolites has been achieved by passing an inert gas (nitrogen) with controlled relative humidity through the NOloaded zeolites. It was stated that the relative humidity of the gas as well as the chemical composition of the zeolite is important in controlling the release rate of the adsorbed NO [63]. The irreversibly adsorbed NO was released by contacting the NO-loaded NZ with water was also reported in our previous study [66]. NO and $\mathrm{NO}_{2}$ coadsorbed in $\mathrm{Na}-\mathrm{Y}$ zeolite as $\mathrm{N}_{2} \mathrm{O}_{3}$ was displaced by competitively adsorbed water molecules from a hydrated air stream (5-40\% water) at the adsorption temperature. The water content of the flushing stream and the stripping gas flow rate are key process parameters. Generation of a high partial pressure of steam by liquid water injection in the bed of $\mathrm{N}_{2} \mathrm{O}_{3}$ saturated $\mathrm{Na}-\mathrm{Y}$ led to immediate desorption of the NOx, which can then easily be evacuated with a small stream of dry air [26].

\section{Conclusions}

In the present study, NO adsorption equilibrium and kinetic parameters for a local clinoptilolite-rich natural zeolitic material from Turkey (Gördes deposit) were determined by the concentration pulse chromatography method. Under the experimental conditions (carrier gas velocities and bed temperatures) the micropore diffusion resistance was found to be the mass transfer controlling step. Therefore it was possible to determine the micropore diffusion coefficient and activation energy for diffusion of NO in the micropores of clinoptilolite.

From inspection of the retention times and areas of the response peaks obtained from successive NO pulses, it was shown that NO is adsorbed in clinoptilolite irreversibly.

The reversibly adsorbed NO could be desorbed by purging with a nonadsorbing inert gas at the adsorption pressure and temperature. Temperature programmed desorption profile obtained by heating the NO-saturated adsorbent to $400{ }^{\circ} \mathrm{C}$ under inert flow revealed presence of multiple irreversibly adsorbed species in NZ with different thermal stabilities. Presence of other irreversibly adsorbed species that could be desorbed above $400{ }^{\circ} \mathrm{C}$ was also interpreted from the TPD profile. The strong interaction of $\mathrm{NO}$ with the clinoptilolite-rich natural zeolitic material makes this material suitable for NO storage rather than for cyclic adsorptive separation processes.

\section{Acknowledgements}

This study was financially supported by Turkish Republic Prime Ministry State Planning Organization (DPT-2006K120690, Determination of Effects of Zeolite on Health on Cellular and Molecular Level).

\section{Appendix A. Supplementary data}

Supplementary data related to this article can be found at http:// dx.doi.org/10.1016/j.micromeso.2016.07.007. 


\section{References}

[1] H. Bosch, F. Janssen, Catal. Today 2 (1988) 369-379.

[2] L.K. Keefer, Nat. Mater. 2 (2003) 357-358.

[3] M.A. Gómez-García, V. Pitchon, A. Kiennemann, Environ. Int. 31 (2005) 445-467.

[4] S. Sato, Y. Yu, H. Yahiro, N. Mizuno, M. lwamoto, Appl. Catal. 70 (1991) L1-L5.

[5] M. lwamoto, H. Hamada, Catal. Today 10 (1991) 57-71.

[6] M. lwamoto, H. Yahiro, Catal. Today 22 (1994) 5-18.

[7] H. Hamada, Y. Kintaichi, M. Sasaki, T. lto, M. Tabata, Appl. Catal. 70 (1991) L15-L20.

[8] H.K. Shin, H. Hirabayashi, H. Yahiro, M. Watanabe, M. lwamoto, Catal. Today 26 (1995) 13-21.

[9] Y. Li, J.N. Armor, Appl. Catal. B Environ. 2 (1993) 239-256.

[10] F. Witzel, G.A. Sill, W.K. Hall, J. Catal. 149 (1994) 229-237.

[11] C. Yokoyama, M. Misono, B. Chem. Soc. Jpn. 67 (1994) 557-562.

[12] A. Corma, A.E. Palomares, V. Fornés, Res. Chem. Intermediat. 24 (1998) 613-623.

[13] F. Gao, N.M. Washton, Y. Wang, M. Kollár, J. Szanyi, C.H.F. Peden, J. Catal. 331 (2015) 25-38.

[14] D.S. Krivoruchenko, N.S. Telegina, D.A. Bokarev, A.Y. Stakheev, Kinet. Catal. 56 (2015) 741-746.

[15] I. Ellmers, R. Pérez Vélez, U. Bentrup, W. Schwieger, A. Brückner, W. Grünert Catal. Today 258 (2015) 337-346.

[16] A.N. Mendes, A. Matynia, A. Toullec, S. Capela, M.F. Ribeiro, C. Henriques, P. Da Costa, Appl. Catal. A Gen. 506 (2015) 246-253.

[17] P. Boroń, L. Chmielarz, S. Dzwigaj, Appl. Catal. B Environ. 168-169 (2015) $377-384$.

[18] J.R. Di Iorio, S.A. Bates, A.A. Verma, W.N. Delgass, F.H. Ribeiro, J.T. Miller, R. Gounder, Top. Catal. 58 (2015) 424-434.

[19] M. Iwamoto, H. Yahiro, N. Mizuno, W.-X. Zhang, Y. Mine, H. Furukawa S. Kagawet, J. Phys. Chem. 96 (1992) 9360-9366.

[20] A. Heyden, N. Hansen, A.T. Bell, F.J. Keil, J. Phys. Chem. B 110 (2006) 17096-17114.

[21] M. Rivallan, G. Ricchiardi, S. Bordiga, A. Zecchina, J. Catal. 264 (2009) 104-116.

[22] W.J. Hong, M. Ueda, S. Iwamoto, S. Hosokawa, K. Wada, H. Kanai, H. Deguchi, M. Inoue, Appl. Catal. B Environ. 106 (2011) 142-148.

[23] M.T. Javed, N. Irfan, B.M. Gibbs, J. Environ. Manage 83 (2007) 251-289.

[24] N. Takahashi, H. Shinjoh, T. Iijima, T. Suzuki, K. Yamazaki, K. Yokota, H. Suzuki, N. Miyoshi, S. Matsumoto, T. Tanizawa, T. Tanaka, S. Tateishi, K. Kasahara, Catal. Today 27 (1996) 63-69.

[25] E. Kayhan, S.M. Andonova, G.S. Senturk, C.C. Chusuei, E. Ozensoy, J. Phys. Chem. C 114 (2010) 357-369.

[26] J.F. Brilhac, A. Sultana, P. Gilot, J.A. Martens, Environ. Sci. Technol. 36 (2002) $1136-1140$.

[27] T. Rudolf, A. Pöppl, W. Brunner, D. Michel, Magn. Reson. Chem. 37 (1999) S93-S99.

[28] A. Sultana, R. Loenders, O. Monticelli, C. Kirschhock, P.A. Jackobs, J.A. Martens, Angew. Chem. Int. Ed. 39 (2000) 2934-2937.

[29] H. Deng, H. Yi, X. Tang, Q. Yu, P. Ning, L. Yang, Chem. Eng. J. 188 (2012) 77-85.

[30] H. Yi, H. Deng, X. Tang, Q. Yu, X. Zhou, H. Liu, J. Hazard. Mater. 203-204 (2012) 111-117.

[31] S. Furuyama, T. Morimoto, J. Phys, Chem. 82 (1978) 1748-1752.

[32] S. Furuyama, K. Sato, J. Phys. Chem. 86 (1982) 2498-2503.

[33] S. Furuyama, M. Miyazaki, H. Inoue, J. Phys. Chem. 88 (1984) 1741-1744.

[34] S. Furuyama, M. Nagato, J. Phys. Chem. 88 (1984) 1735-1740.

[35] Y. Li, J.N. Armor, Appl. Catal. B Environ. 3 (1993) 55-60.

[36] H. Arai, M. Machida, Catal. Today 22 (1994) 97-109.

[37] W.-X. Zhang, H. Yahiro, N. Mizuno, J. Izumi, M. Iwamoto, Langmuir 9 (1993) $2337-2343$.

[38] W. Zhang, H. Yahiro, M. Iwamoto, J. Izumi, J. Chem. Soc. Faraday T 91 (1995) $767-771$.

[39] W. Zhang, M. Jia, J. Yu, T. Wu, H. Yahiro, M. Iwamoto, Chem. Mater. 11 (1999) 920-923.

[40] A. Matsumoto, M. Sano, N. Nishimiya, K. Tsutsumi, Adsorption 6 (2000) $251-257$.

[41] H. Yahiro, M. Iwamoto, Appl. Catal. A Gen. 222 (2001) 163-181.

[42] J. Despres, M. Koebel, O. Kröcher, M. Elsener, A. Wokaun, Microporous Mesoporous Mater. 58 (2003) 175-183.

[43] J.D. Henao, L.F. Córdoba, C.M. De Correa, J. Mol, Catal. A Chem. 207 (2004) 195-204.

[44] A. Shichi, A. Satsuma, T. Hattori, Catal. Today 93-95 (2004) 777-781.

[45] V. Umamaheswari, M. Hartmann, A. Pöppl, J. Phys. Chem. B 109 (2005) $1537-1546$.
[46] E. Ivanova, K. Hadjiivanov, S. Dzwigaj, M. Che, Microporous Mesoporous Mater. 89 (2006) 69-77.

[47] N. Wilken, K. Kamasamudram, N.W. Currier, J. Li, A. Yezerets, L. Olsson, Catal. Today 151 (2010) 237-243.

[48] J. Yang, T.T. Zhuang, F. Wei, Y. Zhou, Y. Cao, Z.Y. Wu, J.H. Zhu, C. Liu, J. Hazard. Mater. 162 (2009) 866-873.

[49] X. Chang, G. Lu, Y. Guo, Y. Wang, Y. Guo, Microporous Mesoporous Mater. 165 (2013) 113-120.

[50] M.W. Ackley, S.U. Rege, H. Saxena, Microporous Mesoporous Mater. 61 (2003) 25-42.

[51] G. Klopp, J. Siito, K. Szasz, I. Szebenyi, G. Winkler, M. Machacs, G. Palmai, United States Patent 4367204, 1983.

[52] G.V. Tsitsishvili, T.G. Andronikashvili, G.N. Kirov, L.D. Filizova, Natural Zeolites, Ellis Horwood, New York, 1992.

[53] J.R. Kiovsky, P.B. Koradia, United States Patent 4059543, 1977.

[54] R. Hernández-Huesca, G. Aguilar-Armenta, G. Dominguez, Sep. Sci. Technol. 44 (2009) 63-74.

[55] G. Domínguez, R. Hernández-Huesca, G. Aguilar-Armenta, J. Mex. Chem. Soc. 54 (2010) 111-116.

[56] R. Moreno-Tost, J. Santamaría-González, E. Rodríguez-Castellón, A. JiménezLópez, M.A. Autié, E. González, M.C. Glacial, C.D.L. Pozas, Appl. Catal. B Environ. 50 (2004) 279-288.

[57] R.Q. Long, R.T. Yang, J. Catal. 207 (2002) 274-285.

[58] S.H. Hyun, R.P. Danner, Ind. Eng. Chem. Fund. 24 (1985) 95-101.

[59] R.W. Triebe, F.H. Tezel, Gas. Sep. Purif. 9 (1995) 223-230.

[60] R.W. Triebe, F.H. Tezel, A. Erdem-Senatalar, A. Sirkecioglu, Stud. Surf. Sci. Catal. 98 (1995) 219-220.

[61] M.A. Galán, Chem. Eng. J. 28 (1984) 105-113.

[62] Y.H. Ma, C. Mancel, AIChE J. 18 (1972) 1148-1153.

[63] P.S. Wheatley, A.R. Butler, M.S. Crane, S. Fox, B. Xiao, A.G. Rossi, I.L. Megson, R.E. Morris, JACS 128 (2006) 502-509.

[64] B. Xiao, P.S. Wheatley, R.E. Morris, Stud. Surf. Sci. Catal. 170 (2007) 902-909.

[65] S. Fox, T.S. Wilkinson, P.S. Wheatley, B. Xiao, R.E. Morris, A. Sutherland, A.J. Simpson, P.G. Barlow, A.R. Butler, I.L. Megson, A.G. Rossi, Acta Biomater. 6 (2010) 1515-1521.

[66] G. Narin, C.B. Albayrak, S. Ülkü, Appl. Clay Sci. 50 (2010) 560-568.

[67] D.M. Ruthven, Principles of Adsorption and Adsorption Processes, John Wiley \& Sons, New York, 1984

[68] S. Chapman, T.G. Gowling, Mathematical Theory of Non-uniform Gases, second ed., Cambridge University Press, Cambridge, 1951.

[69] R.T. Yang, Gas Separation by Adsorption Processes, Butterworth Publishers, Stoneham, MA, 1987.

[70] J.V. Smith, in: J.A. Rabo (Ed.), Zeolite, Chemistry and Catalysis, ACS Monograph 171, American Chemical Society, Washington, 1976, pp. 3-79.

[71] D.W. Breck, Zeolite Molecular Sieves, John Wiley \& Sons, New York, 1974.

[72] A. Sirkecioglu, Y. Altav, A. Erdem-Senatalar, Sep. Sci. Technol. 30 (1995) 2747-2762.

[73] F.A. Mumpton, in: D. Kallo, H.S. Sherry (Eds.), Occurrence, Properties, and Utilization of Natural Zeolites, Akademia Kiado, Budapest, 1998, pp. 333-366.

[74] M. Suzuki, Adsorption Engineering, Elsevier, Amsterdam, 1990.

[75] M.W. Ackley, R.T. Yang, AlChE J. 37 (1991) 1645-1656.

[76] D.M. Ruthven, Microporous Mesoporous Mater. 162 (2012) 69-79.

[77] J. Kärger, D.M. Ruthven, Diffusion in Zeolites and Other Microporous Solids, John Wiley \& Sons, New York, 1992.

[78] Ş.Ç. Sayılgan, M. Mobedi, S. Ülkü, Microporous Mesoporous Mater. 224 (2016) 9-16.

[79] J.A. Delgado, V.I. Águeda, M.A. Uguina, J.L. Sotelo, P. Brea, C.A. Grande, Ind. Eng. Chem. Res. 53 (2014) 15414-15426.

[80] V.I. Agueda, J.A. Delgado, M.A. Uguina, P. Brea, A.I. Spjelkavik, R. Blom, R.C. Grande, Chem. Eng. Sci. 124 (2015) 159-169.

[81] K. Chihara, M. Suzuki, K. Kawazoe, AIChE J. 24 (1978) 237-246.

[82] D. Biglino, M. Bonora, A. Volodin, A. Lund, Chem. Phys. Lett. 349 (2001) $511-516$.

[83] K. Kaneko, Colloid. Surf. 37 (1989) 115-124.

[84] J. Alcañiz-Monge, A. Bueno-López, M.A. Lillo-Rodenas, M.J. Illán-Gómez, Microporous Mesoporous Mater. 108 (2008) 294-302.

[85] K. Hadjiivanov, B. Tsyntsarski, T. Nikolova, PCCP 1 (1999) 4521-4528.

[86] J.H. Lunsford, P.J. Hutta, M.J. Lin, K.A. Windhorst, Inorg. Chem. 17 (1978) 606-610.

[87] E. Ivanova, K. Hadjiivanov, D. Klissurski, M. Bevilacqua, T. Armaroli, G. Busca, Microporous Mesoporous Mater. 46 (2001) 299-309.

[88] P.A. Redhead, Vacuum 12 (1962) 203-211.

[89] J.A. Konvalinka, J.J.F. Scholten, J.C. Rasser, J. Catal. 48 (1977) 365-373.

[90] H.E. Kissinger, Anal. Chem. 29 (1957) 702-1706. 